\title{
Application of through-time spiral GRAPPA to phase velocity mapping (PVM)
}

\author{
Robin Simpson ${ }^{1 *}$, Jennifer Keegan ${ }^{1}$, Nicole Seiberlich², David Firmin ${ }^{1}$ \\ From 17th Annual SCMR Scientific Sessions \\ New Orleans, LA, USA. 16-19 January 2014
}

\section{Background}

PVM is an established technique for measuring blood [1] and myocardial velocities [2]. However, long scan times can restrict its application. Peak-GRAPPA has been used to accelerate Cartesian PVM up to a factor of $6(R=6)$ without degrading peak velocity measurements [3], however use of efficient k-space trajectories could allow higher temporal resolution (TR) in similar scan time. Through-time spiral GRAPPA allows highly accelerated spiral data to be reconstructed using throughtime calibration information [4]. By collecting multiple repetitions of fully sampled calibration data, which can be collected without gating during free breathing, through-time information can be used to generate GRAPPA weights specific to the local undersampling in the non-Cartesian data. This abstract presents preliminary work on a single volunteer to apply this reconstruction to myocardial spiral PVM data.

\section{Methods}

Data for phase velocity mapping were collected on a 3T Skyra MRI scanner (Siemens Medical Solutions, Erlangen, Germany) with 18 receiver channels. Fullysampled k-space was made up of eight spiral interleaves, each of $14 \mathrm{~ms}$ duration, with acquired spatial resolution of $1.7 \times 1.7 \mathrm{~mm}$. Calibration data were collected (without ECG gating) by acquiring all eight spirals sequentially 30 times without velocity encoding. PVM data, including velocity compensated data and three directions of encoded data, were undersampled by a factor of two (four out of the eight interleaves) and acquired during a 16 heartbeat breath-hold with TR of $24 \mathrm{~ms}$. Through time spiral GRAPPA recon- structions were performed at $\mathrm{R}=2$, and on data retrospectively undersampled to $\mathrm{R}=4$ (two spiral interleaves) and $\mathrm{R}=8$ (one interleaf). The reconstructed images were analysed and compared to a CGSENSE [5] $R=2$ reconstruction of the same data without background correction.

\section{Results}

Figure 1 shows global longitudinal, radial and circumferential peak velocities measured using images generated by the four reconstructions (through-time spiral GRAPPA $\mathrm{R}=2, \mathrm{R}=4$, and $\mathrm{R}=8$, and CG SENSE $\mathrm{R}=$ 2), while Table 1 shows measured global peak velocities. The curves have very similar shapes in all cases. All peak velocities are well preserved up to $\mathrm{R}=4$, and some are also well preserved at $\mathrm{R}=8$ (Long1, Circ1, $\operatorname{Rad} 2$ ). However some of the peaks (Long2, Rad1, Circ2) are beginning to be degraded by $\mathrm{R} 8$.

\section{Conclusions}

Through-time spiral GRAPPA can be used to accelerate spiral PVM acquisitions. In this example very little degradation of peak velocities was seen up to R4 and results at higher factors could be improved with further optimisation. Spiral trajectories have allowed higher TR than was possible in a similar breath-hold duration with peak-GRAPPA accelerated Cartesian tissue PVM acquisitions [3] (24 ms vs $70 \mathrm{~ms}$ ). This technique shows great potential for the acceleration of spiral PVM.

\section{Funding}

Robin Simpson is funded by HRUK grant RG2584. 


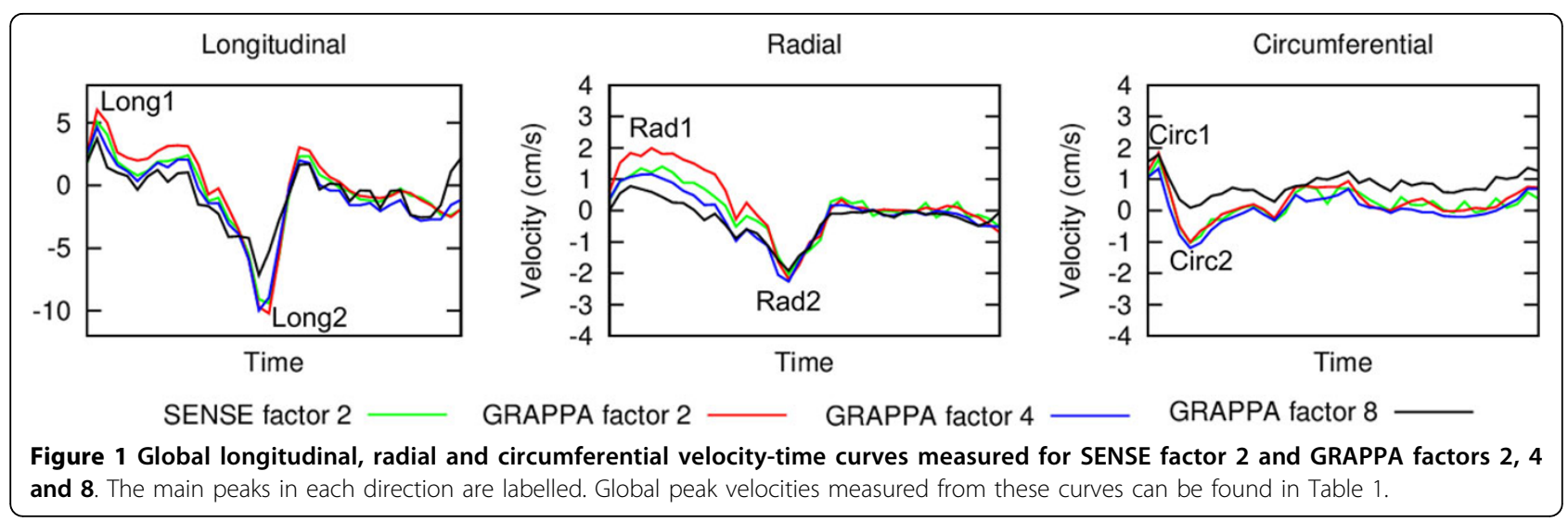

Table 1 Global peak velocities measured with the various reconstructions

\begin{tabular}{ccccc}
\hline Peak & SENSE R2 $(\mathbf{c m} / \mathbf{s})$ & GRAPPA R2 $\mathbf{( c m} / \mathbf{s})$ & GRAPPA R4 (cm/s) & GRAPPA R8 (cm/s) \\
\hline Long1 & 5.08 & 6.03 & 4.64 & 3.73 \\
\hline Long2 & -9.40 & -10.2 & -9.97 & -7.16 \\
\hline Rad1 & 1.40 & 1.99 & 1.16 & 0.78 \\
\hline Rad2 & -2.03 & -2.19 & -2.26 & -1.92 \\
\hline Circ1 & 1.63 & 1.84 & 1.34 & 1.78 \\
\hline Circ2 & -1.04 & -1.01 & -1.19 & 0.09 \\
\hline
\end{tabular}

\section{Authors' details}

${ }^{1}$ CMR Royal Brompton Hospital, Imperial College, London, London, UK. ${ }^{2}$ Dept of Biomedical Engineering, Case Western Reserve University, Cleveland, Ohio, USA.

Published: 16 January 2014

\section{References}

1. Gatehouse: Eur Radiol 2005.

2. Simpson: JMRI 2013.

3. Jung: MRM 2008.

4. Seiberlich: MRM 2011.

5. Sorensen: IEEE Trans Med 2009.

doi:10.1186/1532-429X-16-S1-W20

Cite this article as: Simpson et al: Application of through-time spiral GRAPPA to phase velocity mapping (PVM). Journal of Cardiovascular Magnetic Resonance 2014 16(Suppl 1):W20.

Submit your next manuscript to BioMed Central and take full advantage of:

- Convenient online submission

- Thorough peer review

- No space constraints or color figure charges

- Immediate publication on acceptance

- Inclusion in PubMed, CAS, Scopus and Google Scholar

- Research which is freely available for redistribution 